\title{
Research on Urban Vehicle Art Design and Development Based on Local Culture
}

\author{
Qing Wu, Ming Lei \\ College of art and design, Wuhan University of Science and Technology, Wuhan, China
}

Keywords: local culture; vehicle; art design.

\begin{abstract}
This paper discusses the relationship between local culture and urban vehicle art design, and studies the development trend of urban vehicle art design. The aim is to discuss the significance of the localization of urban vehicle art design and explore the influence of the prosperity and development of local culture on vehicle art design. Based on the study of local culture characteristics and essence, the paper explores the ways to extract the elements of local culture into the vehicle art design. By applying the system in the local culture and art design combined with vehicle, the integration of local culture will add people to the vehicle's identity. It is beneficial to set up a domestic car brand. The combination of native culture and technology will drive the vehicle intelligent and promote diversity of the vehicle.
\end{abstract}

\section{Introduction}

Since the birth of the first car in the world, car development history has been more than 100 years. The art of automotive design is closely related to culture. Car as the main means of transportation has been in constant progress and improvement. Automobile culture has been gradually flourishing around the world and has become an important part of popular culture. Now the development of art design of the vehicle is not only a function of perfect, more important is the combination of science and technology and cultural connotation, in the very long period of time China's vehicle model and brand design has always been imitating and copying foreign models, on the streets of the city can see all kinds of foreign brands vehicles come and go, but domestic brand vehicle rarely, as automotive production and sales of the first countries in the world, vehicle localization has yet to be in-depth study of artistic design, still lack of influential brands in the world. Chinese automobile designers are responsible and have the obligation to excavate mainland culture, study local culture design philosophy and aesthetics, and explore the way to blend the abundant, profound Chinese culture into automobile design. With the fuse of 'the combination of the appearance and spirit' of Chinese art design and the streamline of car body, the design will highly meet the modern people's design concept and aesthetic standard. By absorbing local culture's quintessence, it is possible to design cars which meet the aesthetics of modern customers, and build national brand of car, in order to push Chinese automobile design to the world.

\section{The philosophy and aesthetics idea of local culture}

Different from traditional culture, local culture is an unique culture form which grows from the combination of traditional Chinese culture, with distinct national strategy. China has deep, abundant local culture, which has become treasury of modern design. Studying local culture is to retrospect the design philosophy, aesthetics idea, aesthetics psychology, national spirit and colorful folk arts. The influence of local culture to automobile design is multidimentional and multilevel. Chinese local culture has deep origin with Confucianism, Taoism and Buddhism, and these philosophies deeply influence Chinese value and aesthetics psychology. Confucianism's core aesthetics philosophy are 'moderation' and 'harmonious', which emphasize in nature and harmony. Taoism's nature-human integration, obeying the nature rule is indispensable to modern automobile design. 


\section{Local culture and car art design}

In modern life, cars are not only transportation tools, but also the wind indicator of time spirit, car art in each age coordinate the age's culture, and the car itself becomes the disseminator of city culture. Culture elements in automobile design are not used mechanically, which needs to deep re-interpret culture, and mixed with modern science creatively, and transmit local culture spirit artistically. Fully understanding local culture's social value, firmly believing the local development of automobile design, building the faith of going abroad of local brand, need foresight of development and scientific methods. Throughout the history of foreign automobile design development, localization is an essential way. Developed countries built their famous car brands were based on their local culture, which worth drawing lessons from, like Benz, BMW, Peugeot, which all have their own family symbols. Benz has horizontal grid. BMW has double-kidney shaped air grid. Peugeot has its unique eagle front light. To create national characteristics of Chinese brand, it is essential to design the high recognition car modelling.

Now car art of design is not only beautifying shape and color, but also the sublime of local culture, with strongly relate to politics, economics, scientific technology. First we need to build the confidence of local culture, then absorbing local art's quintessence, extract and purify the quintessence to automobile design, reinterpret the meaning of local culture in modern design. Local art concept is the foundation of Chinese car art design, it will determine the location of car, and is the key to develop, which will become the national style of car art design.

The history of Chinese automobile design is not long, the fact showed the localization of automobile design is the key to develop car industry. The first Chinese local automobile design appeared in Red Flag, there is mixture of national element from brand name to car modeling. The second one is Dongfeng Motor. Dongfeng's symbol is a successful local design example. Shown as fig 1, Dongfeng car symbol, with the art of deformation, use the shape of flying swallow as the basic design, which means double swallow dancing with east wind, which makes people imagine the view of warm wind from east, and swallow dancing in spring. This symbol tells the ambition of Dongfeng Motor which intend to rise from China and fly around the world like swallows. This is the quintessence of Dongfeng Motor's local culture design. Absorbing the culture philosophy of harmony, nature, liberality which accord with Chinese aesthetics, and combine with modern scientific technology, which make Chinese automobile design not only owns national feature, but also have advanced science feeling, that will help Chinese cars go abroad to the world. To highlight local element, BYD Motor develop motorcycle type named 'Qing', 'Tang', 'Song', 'Yuan'. These car types bravely use the Chinese element in modelling and inner design, especially use Chinese words as their name, which gives a good start for native brands. Shown as fig 2, 'Song' uses 'X' sculpt in front face, which is easily recognized. Hexagon air grid with big lamp on both side, which looks very special. The flank line looks fluent, and the back lamp looks great as well. On the Steering wheel, there is a red word 'Song', which shows the identity of this car.

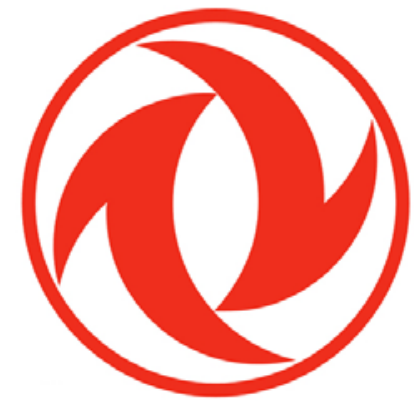

Fig 1 Dongfeng Motor's Logo

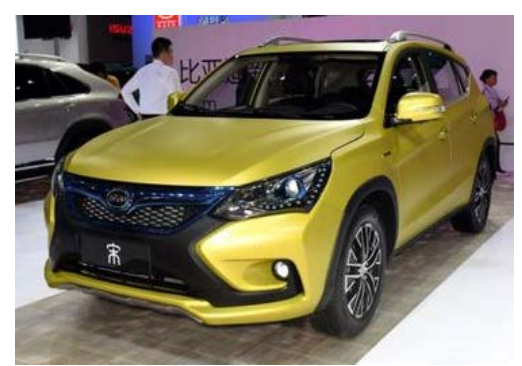

Fig 2 Biyadi Song

To achieve the goal of localize of car art design, we must take scientific and proper ways, step by step to make good local design. Comprehensively consider the function and modeling of cars, will combine the local culture with design procedure. Specific ways are shown as fig 3. 


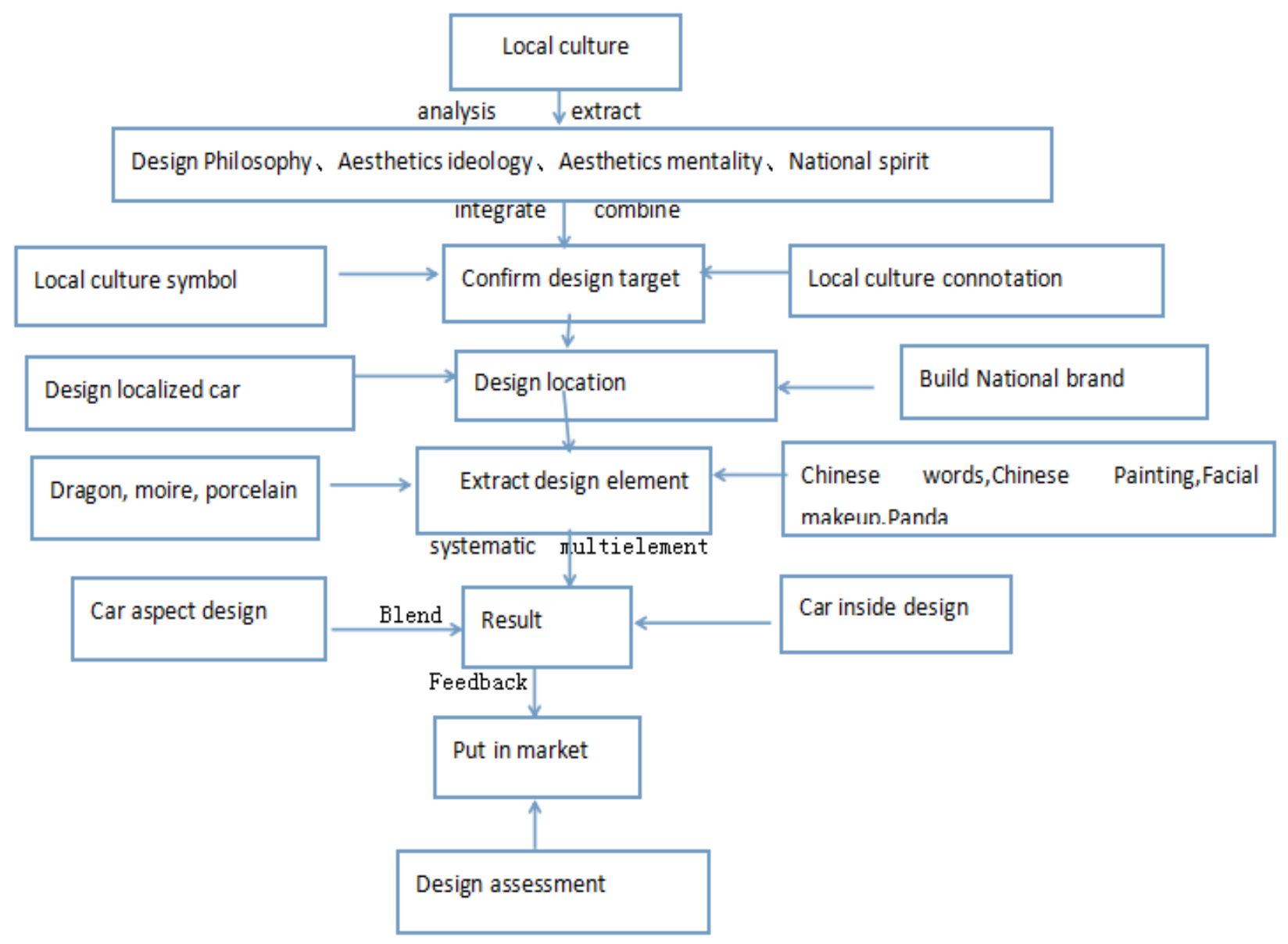

Fig 3 Automobile local design method and procedure

\section{The direction of city automobile design}

The nature-human integration of ecology design idea in local culture guides the automobile design. Now, automobile will change in many aspects to adapt the developing world. The cars in the future must have the advantage of environmental clean, intelligent, easy to communicate, and mix joy together with drive, the automobile culture will have strong influence to customers' aesthetic taste. The compact car modelling with comfortable space is the core design element in the future. Lower baseboard, wider car body, and lighter the weight, the car in the future will apply carbon fiber as material. 3D print technology will make the production of car component more efficient and cheaper, the design of automobile will be more humanity and personality.

The green automobile design is a systematic, complicated project. New fuel car is an important trend for green design. Geely Panda electric car is a typical case as car local design. Geely Panda take 'big mouth' design, the whole car looks round and flowing, which shows naive and lovely of panda. The front lights are surrounded by black line, which looks like panda's eye shadow, the tail lights are designed as the foot of panda, which constitute a whole 'panda'. This plug-in hybrid car has bright future, by using electric mode in short trip while using oil mode in long trip.

Based on investigation, most of customers want their car modeling in the future have modern sense, the other few likes simplicity or luxury. A lot of customers believe the individuality of car design is the new trend. The car design trend will obviously include green, virtual, interaction and personality, digitization and intelligent development, their relationship is very close to each other. Only consider each aspect element, the designer can design convenient and fun cars. 


\section{New stereotype urban vehicle art design}

According to different types of vehicle, what had already been designed are listed below:

\subsection{Family electrical car}
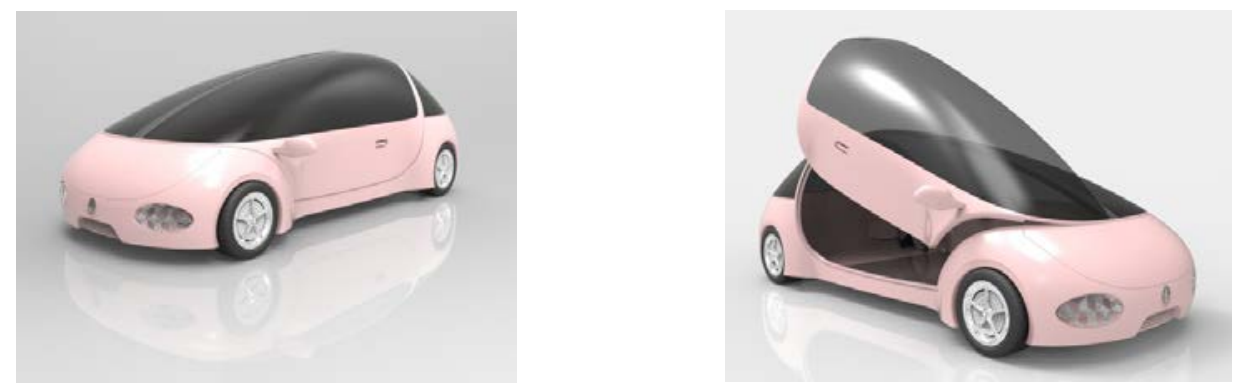

Fig.4 Pink Marry electrical car

As shown in figure 4, this is one type of vehicle which designed specifically for city female drivers so that the pink colour has been chosen. During driving drip, the broad vision, light weight car design and the whole out-shape representing a view which combine mellow and full, smooth, concise and fashion, fully gives expression to a aesthetic idea based on local culture. Especially for the opening mode of the car gate, one gate segment will lift upon which can make passengers and the diver leave the car much more easier and safer. Polycarbonate which shows a transparency look, gives out a strong enough property and also can be easily shaped up was chosen to be used as the material of car roof. By the using of this material, the car weight can be highly reduced.

\subsection{Hybrid power car}

The worship for tiger by Chinese nation has a long history, tiger is the symbol of justice, bold and powerful and stateliness. Chinese people are always fond of the image of tiger. As shown in figure 5, the design idea of the car front face has taken example of the form of tiger, the design form of the automotive lighting and the air inlet grille shows a novel and unique appearance. A grand, sturdiness, and the steady-going feeling, and the pursuing for the harmonious can be easily impressed users if they just looking from the front and the black colour represents mystery and grace. If they look from the side, they can really enjoy the smooth line, the design of the whole modelling which gives out a feeling of solemn and broad. This type of design will highly suit the successful man.
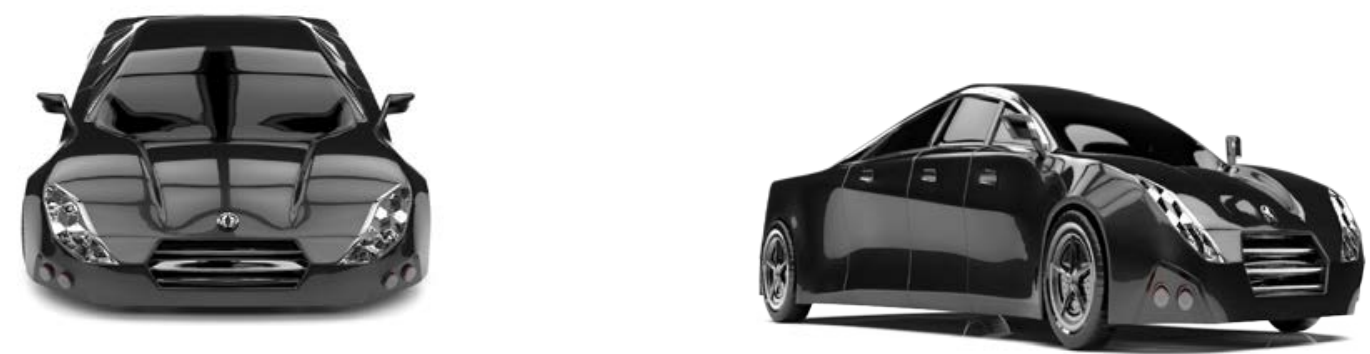

Fig.5 hybrid powered car

\subsection{Urban public bus}

As shown in the figure 6, this bus has a decent, concise, fashion appearance and also gives out a steady driving feeling, it accords with the aesthetic requirement of native culture. The colour choosing is focused on the match of black and white, representing a outstanding and fresh style. In terms of the technology part, more and more electronic technology has been used in public bus and finally making public bus more automatic and intelligent. 


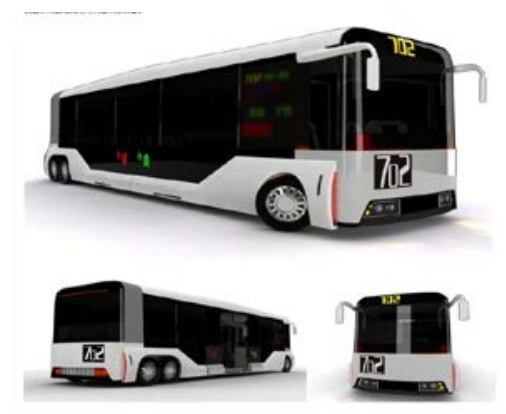

Fig. 6 urban bus

New type of urban vehicle, no matter they are private or public, they all become the obbligato trip tool in people's daily life. The art design of vehicles is a significant part of the fashion culture. The cars' appearance reflect the joy of aesthetic, using diversified design to meet the need of customers from different level, the localization of urban vehicle design can increase people's adaptation of vehicles, representing the spirit of nation and spreading local culture.

\section{The expectation for the future vehicle art design}

There is no doubt that it is important to base our vehicle art design on our native culture. On the basis of the learning for the famous brand designing experience in order to accomplish the localization of vehicle brands in combine with the innovative design for vehicles and finally representing the charming of local culture. The combination of local culture and scientific technology can bring the car design benefit. In the future, the vehicle art design will attract more and more people to step into this area and then bring a blooming of vehicle art design career and the vehicle culture will be more plenty and diversified, there will be more and more choices for people to choose their tripping ways. In the coming future, more and more new energy used car will substitute fuel used car. The humanization of car design will come true. The future vehicle design will show some characteristics below:

Along with the constant development of culture exchange and culture mixture, local culture will also absorb foreign culture which means local culture shows a strong containment. There is no conflict between localization design and international, vehicle design which based on local culture has more universality.

The art design of vehicle should not only inheriting and spreading traditional culture, but also representing fashion and scientific.

With more and more people concerned about develop of nuclear power question, the develop trend of vehicle technology which changing the fuel used car to become different types of nuclear power used car, it will bring different driving experience to divers. New man-machine layout should be built based on ergonomics and then coordinate the mutual relationship of man and vehicle.

The appearance and interior car decoration design should be both diversified and personalized, new material and new technology will be widely used both in the car appearance and decoration. Vehicle art design should both be scientific and full of culture impression. When the overseas car brand decides to step into Chinese market, they all need to be designed in localization mode.

\section{Acknowledgements}

2013 Hubei education department humanities and social science research general project approval: based on ergonomic urban vehicle art design theory and application research (No.: 20130301) 2016 hubei education department humanities and social science research general project approval: Research on the shape design of electric vehicles based on large space of small cars (No.: 16Y017).

\section{References}

[1] Tang jie, et al. Conceptual car development[M]: Beijing, Machinery Industry Press, 2010. 
[2] Michel, future car century[M]. Beijing: Renmin University of China press,2010.

[3] Ling Yong-cheng, et al. Modern car and Automobile culture[M]. Beijing: Tsinghua university press, 2010.

[4] Li jie. The trend of emotional design of cars[J]: Art and Design, 2008(8):168-170.

[5] Lin li. The application of Chinese cultural symbol in car modelling design[J]. Chongqing: Packaging Engineering, 2008.29(12),221-221

[6] Bai yin, et al. talking about Exterior styling of automobile design [J]. Beijing: urban vehicle, 2009.11

[7] Wang shu-de. The application of artistic design aesthetics law in car modeling design[J]. He fei: Anhui literature, 2010(01).

[8] Chen peng. From the development of car modelling to the future automobile design[D]Nanjing university of technology, 2012.

[9] Liu zi -lu. automobile design[M]. Beijing: Tsinghua university press, 2013.

[10] Li xiu-hua, et al. The application of traditional Chinese culture to Auto appearance design[J]. He fei: Journal of Anhui University of Technology2013(02):46-47. 